\title{
Influence of various preparation methods on percolation behavior of systems based on cross-linked polyurethanes and carbon nanotubes
}

\author{
E.A.Lysenkov ${ }^{1}$, E.V.Lobko ${ }^{2}$, V.V.Klepko ${ }^{2}$, I.P.Lysenkova ${ }^{1}$ \\ ${ }^{1}$ Mykolayiv V.Sukhomlynskiy National University, 24 Nikol'ska Str., \\ 54030 Mykolayiv, Ukraine \\ ${ }^{2}$ Institute of Macromolecular Chemistry, National Academy of Sciences of \\ Ukraine, 48 Kharkiv Shausse, 02160 Kyiv, Ukraine
}

Received June 2, 2017

The features of conductivity and percolation behavior of systems based on cross-linked
polyurethanes (CPU) and carbon nanotubes (CNT) depending on the preparation methods are
tudied by methods of impedance spectroscopy and optical microscopy. It is established, that
ntroduction of nanosized laponite in the CPU-CNTs system leads to decrease of the percola-
ion threshold more than three times. The introduction of laponite influences on the size of
CNT aggregates, state of their dispersion and spatial distribution homogeneity. The most
efficient method of the properties improvement is formation of the CPU-CNTs system under
action of direct current (dc) electric field. For the systems, which are formed under the action
of dc electric field the percolation threshold decreases more than five times.

Keywords: polymer nanocomposites, carbon nanotubes, conductivity, percolation behavior, laponite, direct current electric field.

Используя методы импедансной спектроскопии и оптической микроскопии проведено исследование особенностей электропроводимости и перколяционного поведения систем на основе сетчатых полиуретанов (СПУ) и углеродных нанотрубок (УНТ) в зависимости от методов приготовления. Установлено, что введение наноразмерного лапонита в систему на основу СПУ и УНТ приводит к уменьшению порога перколяции в три раза. Введение лапонита влияет на размеры агрегатов из УНТ, их дисперсность и характер распределения. Наиболее эффективный метод улучшения свойств заключается в формировании системы СПУ-УНТ во внешнем постоянном әлектрическом поле. Для систем, сформированных под действием электрического поля, порог перколяции уменьшается более чем в пять раз.

Вплив різних методів приготування на перколяційну поведінку систем на основі сітчастих поліуретанів та вуглецевих нанотрубок. ЕА.Лисенков, Є.В.Лобко, В.В.Клепко, І.П.Лисенкова.

Використовуючи методи імпедансної спектроскопії та оптичної мікроскопії проведено дослідження особливостей електропровідності та перколяційної поведінки систем на основі сітчастих поліуретанів (СПУ) і вуглецевих нанотрубок (ВНТ) залежно від методів приготування. Встановлено, що введення нанорозмірного лапоніту у систему на основу СПУ та ВНТ приводить до зменшення порогу перколяції в три рази. Введення лапоніту впливає на розміри агрегатів з ВНТ, їх дисперсність і характер розподілу. Найбільш ефективний метод поліпшення властивостей полягає у формуванні системи СПУ-УНТ у зовнішньому постійному електричному полі. Для систем, сформованих під дією електричного поля, поріг перколяції зменшується більш ніж у п'ять разів. 


\section{Introduction}

Nanocomposites based on polyurethanes, filled by carbon nanotubes (CNTs), are attractive as materials with improved ionic and thermal conductivity, electrical, optical, and mechanical properties [1,2]. The main obstacle to good functionality of such materials is connected with poor dispersibility of the CNTs in the majority of solvents and low stability of their dispersions caused by the strong Van der Waals interaction between different CNTs [3].

There are plenty of methods aimed at modification of polymeric nanocomposites filled with CNT [4,5]. One of the most promising of them is introduction of inorganic fillers, for example, montmorillonite (MMT) [5] or laponite (LP) [6] into the nanocomposition.

In particular, it was shown that introduction of MMT can significantly improve dispersibility of the CNTs in different media $[5,7]$ and enhance the electrical percolation of the nanotube-based composites [2, 4-6]. The presence of a clay improves dispersity of the CNTs, which can enhance electrophysical, mechanical, rheological and thermal properties of different composites [8].

Stabilization of a hybrid system containing both organic and inorganic fillers, e.g., clay and carbon nanotube [6], was also recently revealed. It was found that the CNTs aggregates can adsorb on MMT platelets, and the presence of MMT changes the state of aggregation of the carbon nanoparticles. Recently, the synthetic clay, laponite was used for improvement of dispersity of the CNTs in water [10] and liquid crystals [11].

The main method to create the CNTs in oriented state is the nanotubes orientation during the nanocomposite formation. The authors of work [12] developed the electrophoretic deposition method to align singlewalled CNTs in dc electric field. The nanotubes were dispersed in a mixture of solvents based on tetrahydrofuran and tetraoctylammonium bromide. When the applied voltage exceeded $100 \mathrm{~V}$, covered with quaternary ammonium nanotubes assembled into stretched bundles, which oriented normally to the electrode surfaces. The authors of work [13] studied the percolative behavior of systems based on polyethylene glycol and carbon nanotubes formed under normal conditions and the action of de electric field. It was found that the percolation threshold decreased from $0.42 \%$ to $0.1 \%$ if nanofilled systems were formed in the electric field, which testified to a substantial alignment of the nanotubes in polymer matrix. Such technique was successfully applied in order to align the CNTs dispersed in the polymer matrix, by improving the functional characteristics of the nanocomposites [14].

This work is devoted to the study of influence of various preparation methods on the conductivity and percolation behavior of polymeric nanocomposites based on polyurethanes and CNTs.

\section{Experimental}

\subsection{Materials}

CPUs were synthesized in two stages. At the first stage prepolymer based on polypropylene glycol with molecular mass 1000 (PPG-1000) and toluene diisocyanate (TDI) $(2,4-/ 2,6$-isomers $=80 / 20)$ was synthesized (Fig. 1). PG-1000 was dried under pressure of $300 \mathrm{~Pa}$ at $393 \mathrm{~K}$ during $3 \mathrm{~h}$. The valence ratio PPG/TDI was $1 / 2$. The prepolymer synthesis was held at $393 \mathrm{~K}$ during $1.5 \mathrm{~h}$ to percent amount of isocyanate groups was $5.9 \%$. The reaction path was controlled for decreasing of isocyanate groups' quantity according to [15].

At the second stage the prepolymer was cross-linked with thimethylol propane (TMP) as cross-linking agent (Fig. 2).

TMP was dried under the pressure at 313-315 K. Then TMP was solved in the prepolymer at $346-348 \mathrm{~K}$ in an oil bath during 20 min with constant mixing in dried argon atmosphere. The valence balance prepolymer/TMP was $3 / 2$. The reaction path was controlled due to [15] or by IR-

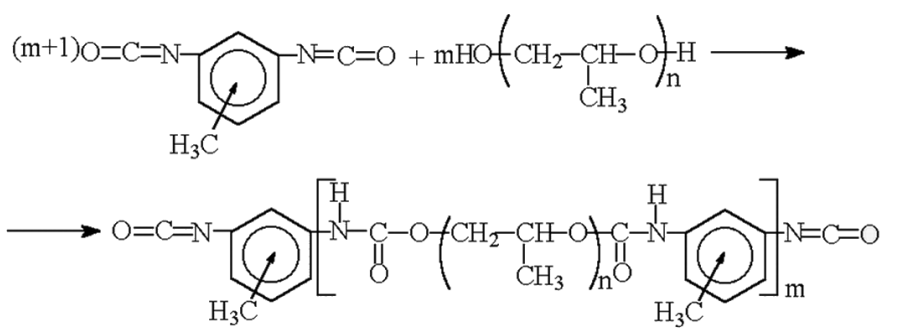

Fig. 1. Synthesis reaction of prepolymer based on PPG-1000 and TDI. 


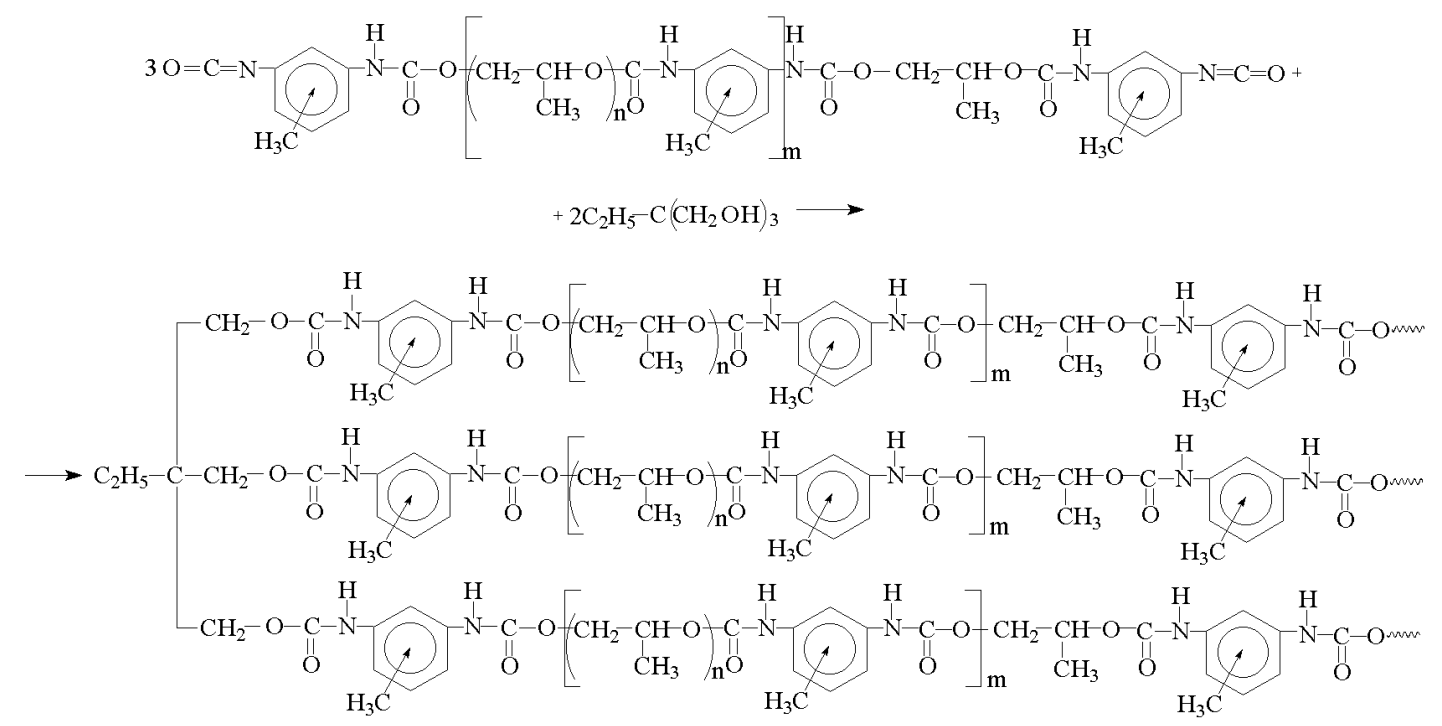

Fig.2. Reaction of prepolymer cross-linkage by TMP with formation of CPU. The fragment of CPU with cross-linkage of junction nodes.

spectrometry "Tensor-37" Bruker with the Furier transforms.

Multi-walled CNTs ("Specmash" Ltd., Ukraine) were made by method of CVD (chemical vapour deposition) with FeAIMo as a catalyst [16]. The CNTs were further treated by alkaline and acidic solutions and washed by distilled water until reaching the distilled water $\mathrm{pH}$ values in the filtrate. The typical outer diameter $d$ of the CNTs was $\approx 30-50 \mathrm{~nm}$ [17], their length $l$ was $\approx 5-$ $10 \mu \mathrm{m}$ and mean aspect ratio was $a=$ $l / d \approx 100-300$. The specific surface area of the powders determined by $\mathrm{N}_{2}$ adsorption was $S=130 \pm 5 \mathrm{~m}^{2} / \mathrm{g}$. Electrical conductivity, $\sigma$, of the CNTs powder compressed at $15 \mathrm{TPa}$ was about $10 \mathrm{~S} / \mathrm{cm}$ along the axis of compression. Density of the CNTs was assumed to be the same as the density of pure graphite, $2045 \mathrm{~kg} / \mathrm{m}^{3}$. The CNTs content in the polymer nanocomposites was varied from $0.02 \%$ to $3 \%$.

Organo-modified Laponite (OLP) was prepared by ion-exchange reactions using cetyltrimethylammoniumbromide

(CTAB, $\mathrm{C}_{16} \mathrm{H}_{33}-\mathrm{N}\left(\mathrm{CH}_{3}\right)_{3} \mathrm{Br}$, Fluka, Germany) with $99.5 \%$ purity as a surfactant. The length of CTAB was $2.33 \mathrm{~nm}$ and its intercalation resulted in increased basal space of the Laponite. The CTAB aqueous solution (1 wt.\%) was slowly added to the aqueous Laponite dispersion (1 wt. \%) and stirred vigorously $24 \mathrm{~h}$ at $360 \mathrm{~K}$.

\subsection{Preparation of composite materials}

The carbon nanotubes were added in the reaction mass as the dispersion in dichloromethane $\left(\mathrm{CH}_{2} \mathrm{Cl}_{2}\right)$. The CNTs dispergation was carried out in two stages using sonicator UZN-22/44 at dispergation frequency $22 \mathrm{kHz}$. In the first stage the carbon nanotubes dispergation was done in $\mathrm{CH}_{2} \mathrm{Cl}_{2}$ (50\% of the sample total mass) for $2.5 \mathrm{~min}$. In the second stage the CNTs dispersion was cooled to room temperature and was added to the reaction mass. The dispergation was continued for $2.5 \mathrm{~min}$. Formation of CPU-CNTs was carried out in Petri dishes at $318 \mathrm{~K}$. The solvent residues were removed from the films by vacuuming of them to constant weight. In the case of triple system CPU-CNTs-OLP, laponite was added at the first stage of sonication.

For investigation of CNTs orientation influence, the specimens of CPU-CNTs mixture were formed in dc electric field. The specimens were placed between two electrodes, which were separated by distance of $3 \mathrm{~cm}$; the voltage difference applied to the electrodes equaled about $30 \mathrm{kV}$. The corresponding strength of the dcEF was about $1 \mathrm{MV} / \mathrm{m}$. The nanocomposites were held under the dcEF action for $1 \mathrm{~h}$ and then cooled down in the electric field.

\subsection{Testing and characterization}

Electric properties of the nanocomposites were investigated by the method of impedance spectroscopy, using impedancemeter Z-2000 (Russia). A sample was placed be- 


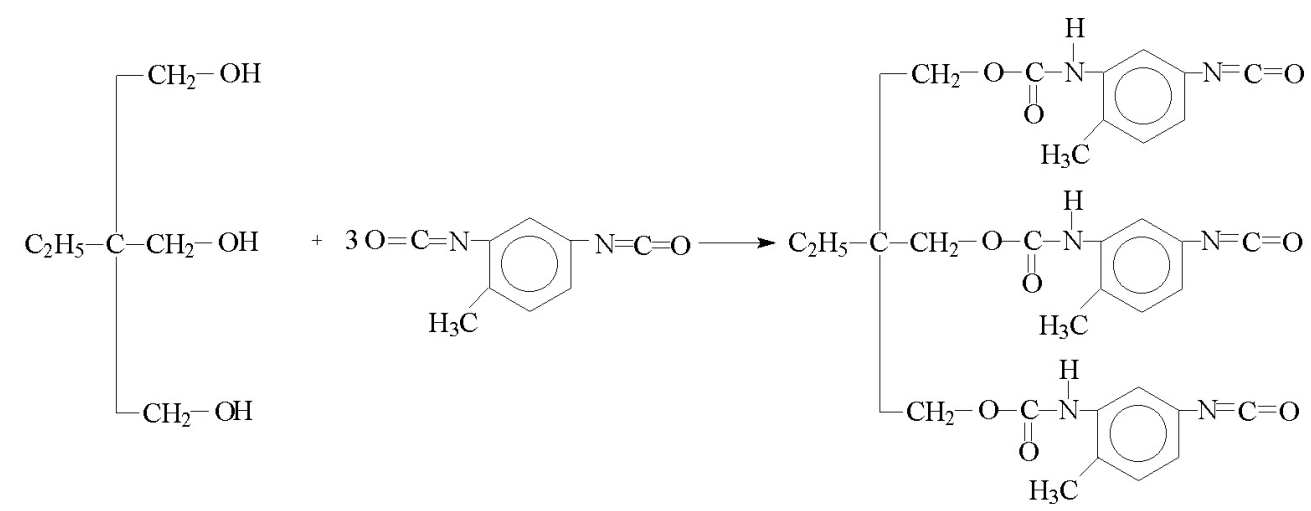

Fig. 3. Reaction of synthesis of adduct based on TDI and TMP.

tween electrodes of cell and measured its real (Z') and imaginary (Z') parts of impedance. From the frequency dependence of complex impedance after the method, described in [18], it was determined a direct current (DC) conductivity $\sigma_{d c}=d / S R_{d c}$, where $S$ was area of a sample, $d$ was a thickness of sample. Measuring carried out at room temperature in the frequency range of $1 \mathrm{~Hz}-2 \mathrm{MHz}$.

Transmittance microphotographs of the CPU based nanocomposites were got using the optical XY-B2 microscope, equipped with ICM 532 digital video eyepiece and by the AMCAP/VIDCAP (Microsoft) system of image treatment. The probed samples were placed in a glass cell with thickness of $100 \mu \mathrm{m}$.

\section{Results and discussion}

\subsection{Influence of method of CPU forming} (prepolymer or adduct)

Two types of the CPU synthesis (through prepolymer and adduct) were applied for studying of their influence on the CPUCNTs composites formation and properties. Synthesis of the CPU-CNTs systems, formed through prepolymer, described in Section 2.

The CPU-CNTs systems synthesis through adduct was conducted as follows. The reactionary forming of the CPU was carried out in two stages. On the first stage the adduct based on TDI and TMP with ratio 3:1 was synthesized (Fig. 3). The synthesis of the adduct was made in ethyl-acetate at $60^{\circ} \mathrm{C}$ during $2 \mathrm{~h}$ while the content of isocyanate groups was equal to $19.0 \pm 0.5 \%$ $\left(\% \mathrm{NCO}_{\text {theor. }}=19.0 \%\right)$.

Initial CPU-0 (adduct) based on the adduct and PPG-1000 was synthesized in $\mathrm{CH}_{2} \mathrm{Cl}_{2}$ for 20 min.

Nanocomposites based on CP (adduct) and CNT were produced in two stages. At

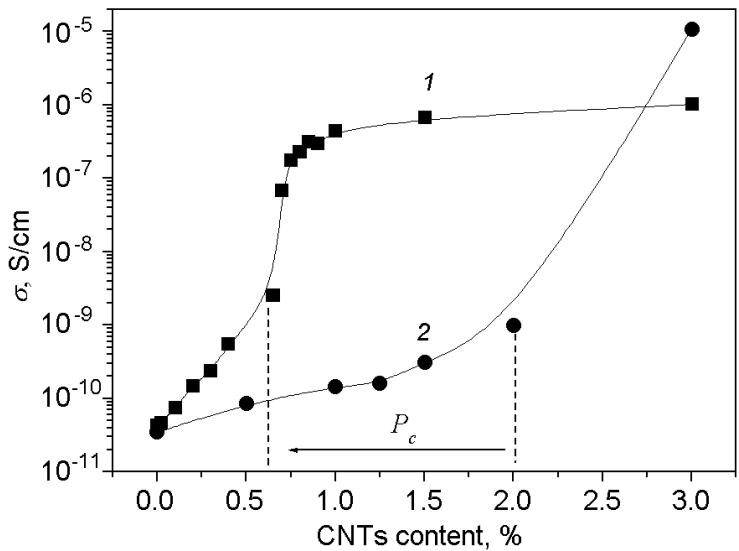

Fig. 4. Conductivity vs. CNTs content for systems based on CPU, formed through prepolymer (1) and adduct (2).

the first stage dispergation of the carbon nanotubes in PPG-1000 was done for 2.5 min using sonicator UZN-22/44 at dispergation frequency $22 \mathrm{kHz}$. At the second stage the expected amount of the adduct in $\mathrm{CH}_{2} \mathrm{Cl}_{2}$ was added to the CNTs dispersion in PPG and continued dispergating during $2.5 \mathrm{~min}$. The reaction of cross-linking was done at room temperature during $20 \mathrm{~min}$. Worth noting, that the CPU, formed through the prepolymer and through the adduct both have an identical chemical structure, as shown in Fig. 2.

In Fig. 4, the dependence of dc conductivity on the filler content for the examined CPU-CNTs systems, formed by different methods is presented. The step-like change of the electro-conductivity is associated with the percolation phenomenon and is observed in concentration intervals of 0.4$0.8 \%$ for the system, formed through the prepolymer, and of 1.5-2.5\% for the system, formed through the adduct. At CNTs content of $3 \%$, the de conductivity of the 
systems is more than five orders of magnitude higher that its values below the percolation threshold. Fig. 4 demonstrates, that the percolation behavior of the investigated systems differs considerably. Differences are observed as for the general level of conductivity so for the values of percolation thresholds $\left(P_{c}\right)$. The value of percolation threshold for the CPU-CNTs system, formed through the adduct is about $2 \%$, while for the system, formed through the prepolymer is $0.63 \%$. Such difference in the values of percolation thresholds can be connected with the types of preparation of the CPUCNTs systems. The prepolymer based on diisocyanate and glycol components is formed on the first stage at the synthesis of CPUCNTs system through the prepolymer. Thus, the polymeric network begins to form and viscosity of the system grows in geometrical progression. At that time, the CNTs are dispersed in solution, separately from the polymer. On the stage of cross-linking of the prepolymer and TMP the dispersion of CNTs is entered by the method of sonication and the usage of the solvent decreases a destructive effect on the polymeric matrix. Thus, separate nanotubes are limited of the polymeric network which hinders their aggregation.

When the CPU-CNTs system is formed through the adduct, sonication of the CNTs is carried out in viscous glycol and then the adduct is added to. In this case the reaction is being gone slower through considerable viscosity of the system, and the nanotubes aggregate more intensively. The CNTs aggregation is stopped in the cross-linking process, but on later stage, than for the system forming through the prepolymer.

\subsection{Influence of laponite}

In [6] it is shown that introduction of low amount $(0.1 \%)$ of organomodified laponite (OLP) in a polyether matrix leads to the considerable decrease of percolation threshold of the system, filled by CNTs. This subsection is devoted to the study of influence of OLP on the percolation behavior of the nanocomposites based on CPU and CNTs.

Dependence of conductivity on the nanofiller content for the probed systems is represented on Fig. 5. The conductivity step-like change is associated with the percolation phenomenon and is observed in the concentration intervals of $0.2-1 \%$. At the CNTs content of $1 \%$, the dc conductivity of the investigated system is more than

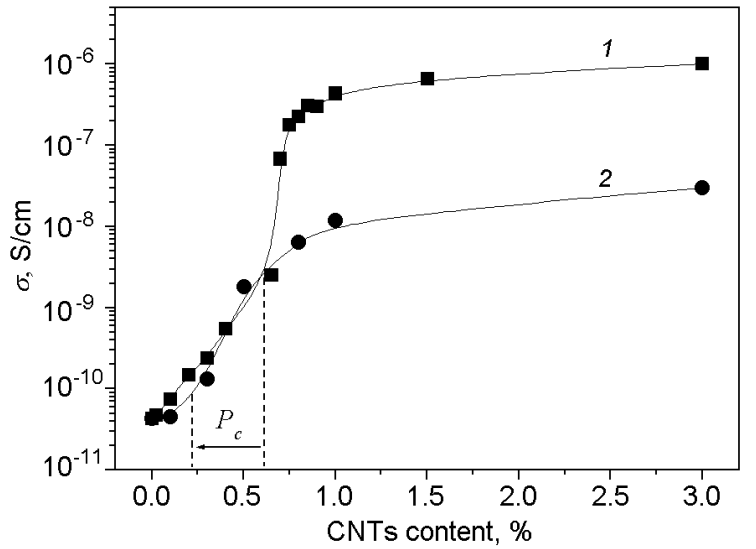

Fig. 5. Conductivity vs. nanofiller content for systems of CPU-CNTs (1) and CPU-CNTs $0.1 \%$ OLP (2).

three orders of magnitude higher than its values below the percolation threshold.

Fig. 5 also shows that with introduction of OLP to the CPU-CNTs system the value of percolation threshold decreases more than three times, from $0.63 \%$ to $0.2 \%$. Such effect is explained by the change of distributing degree of nanotubes in the polymeric matrix volume. The results of conductivity measurements are confirmed the information of optical microscopy. Microphotographs of the CPU-CNTs-OLP systems with the nanofiller content, which close to the percolation threshold, are presented in Fig. 6. We can see from the microphotographs (Fig. 6a), that a continuous cluster from the nanotubes, which pierces all of the volume of standard appears even at the CNTs content, is equal $0.2 \%$. When the CNTs content is equal $0.5 \%$ (Fig. 6b) more branched network from the nanotubes appears, that results in the origin of greater amount of direct contacts between them. At introduction to the material, OLP nanoparticles begin to interact with the surface of nanotubes and attracted to it [10]. As a result of it there is partial coverage of the CNTs surface by the plates of laponite. Worth noting, that at such degree of coverage there is a high probability for formation of direct contacts between the CNTs [6].

At introduction of laponite to the CPUCNTs system, the general level of conductivity after achievement of the percolation threshold appeared considerably below, than for the CPU-CNTs system, which does not contain OLP (Fig. 5). When the CNTs content is equal $1 \%$, conductivity of the system, which contains laponite, is more than two orders of magnitude lower than conduc- 


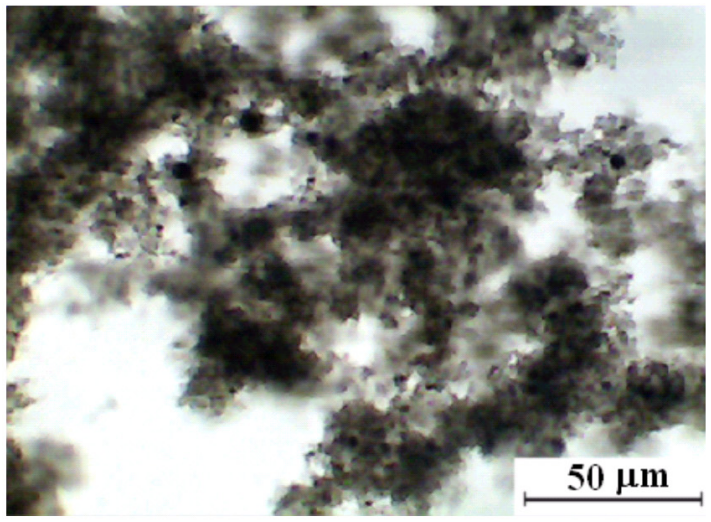

a)

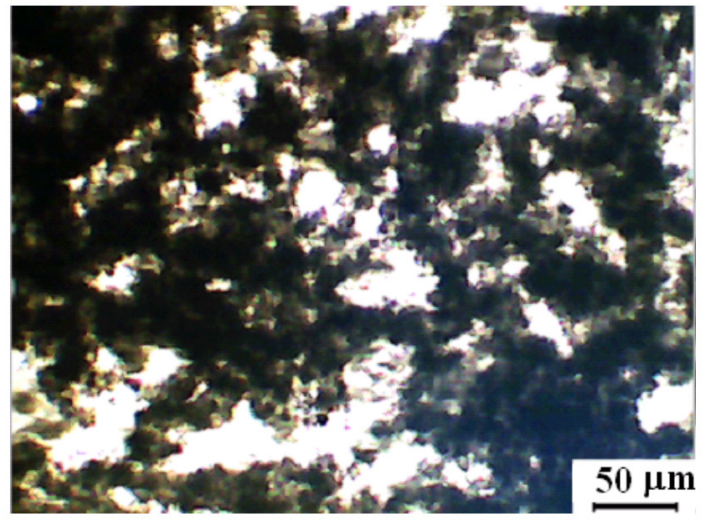

b)

Fig. 6. Photomicrographs of systems based on CPU, which contain $0.1 \%$ OLP and CNTs: a) $0.2 \%$; b) $0.5 \%$.

tivity of the system without OLP. Most probably, that the phenomenon of conductivity decreasing is explained by the fact that OLP platelets wrap around the nanotubes, thus forming the barrier partially preventing the direct contacts of the CNTs and CPU. The similar effects were recently reported for aqueous suspensions of CNTs and laponite [10] and for polymer nanocomposite based on polypropylene glycol and CNTs [6]. Effect of conductivity decreasing is possible to be explained if assuming that the nanoplatelets of laponite form a three-dimensional network in the volume of the material at the high nanofiller content. Consequently, in the process of forming of the CPU-CNTs-OLP system, the laponite platelets interact between themselves and with polymeric molecules, forming the three-dimensional "quasi" network. Thus, the particles of OLP hinder separate the nanotubes to form an own percolation network. In a result, the nanotubes, remaining isolated, can not form the direct contacts between, themselves that leads to the considerable decrease of the system's conductivity.

\subsection{Influence of external dc electric field}

As shown in the literature, dc electric field (dcEF) substantially influences on percolation behavior of the systems based on polymer and CNTs [12-14]. The dependence of $\sigma(p)$ for the CPU-CNTs systems, formed under the action of dcEF and without it is presented in Fig. 7. The resulted graphs show, that the percolation behavior is observed for both types of investigated nanocomposites.

As we can see from Fig. 7, the conducting percolation cluster for the system,

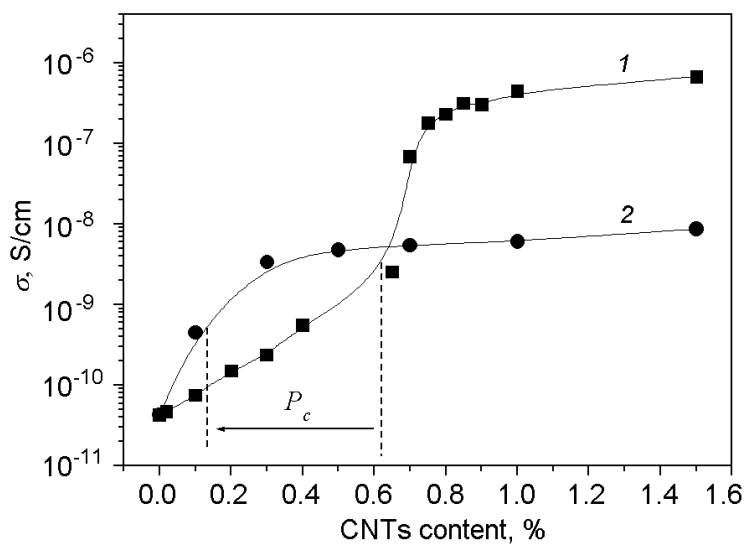

Fig. 7. Conductivity vs. CNTs content for systems based of CPU, formed without dcEF (1) and under action of dcEF (2).

formed under the dcEF action, takes place at lower CNTs concentration, than for the system formed without the dcEF action. The value of percolation threshold for the systems, formed under the dc EF action is $0.12 \%$, while for the systems, formed without the field is $0.63 \%$. This effect takes place due to orientation of the CNTs and their clusters in the dc electric field. Such decreasing of percolation threshold was also observed for the PEG-CNTs system, formed in the electric field [13]. This fact testifies to universality of influence of the dcEF on the percolation behavior of the polyether-containing systems.

However, it is seen from Fig. 7, that conductivity of the CPU-CNTs nanocomposites, formed under the dcEF action, after achievement of the percolation threshold, is considerably less than conductivity of the nanocomposites, formed without the dcEF 
action. Such effect can be explained by two factors which are related to the influence of dcEF on CNTs and on the matrix of CPU. Under the action of powerful dcEF the CNTs try to be orientated along the lines of electric-field tension. As a result, they are disposed parallel each other, that reduces probability of formation of the direct contacts between CNTs. In the systems with the statistical distributing of the CNTs such probability is considerably higher. The dcEF also influences on forming of polymeric network from the chains of PU, which are polar and is forced to move in the electric field. At such moving there is probability, that the chains of PU will destroy the contacts between separate nanotubes due to their mechanical displacing or interaction with their surface which increases the contact resistance.

Consequently, forming of the CPU-CNTs systems under the dcEF action decreases of the percolation threshold, but, at the same time, it considerably reduces the general level of conductivity after the achievement of the percolation threshold.

\section{Conclusions}

Influence of different factors (the method of CPU forming, external electricfield, introduction of nanoclay) on the percolation behavior of systems based on CPU and CNTs has been studied. It is established that value of percolation threshold for the CPU-CNTs system, formed through the adduct is about $2 \%$, while for the system, formed through the prepolymer is $0.63 \%$. Such difference in the percolation thresholds values can be connected with the ways of preparation of CPU-CNTs systems.

Considerable influence on the percolation behavior of the systems based on CPU and CNTs has the introduction of different fillers, for example, organomodified laponite. It is found that the percolation threshold value decreases more than three times from $0.63 \%$ to $0.2 \%$ with introduction of laponite to the CPU-CNTs system. Such effect is explained by the changes of distributing degree of the nanotubes in the volume of polymeric matrix. The results of conductivity are confirmed by the information of optical microscopy.

It is revealed that dc electric field substantially influences on the percolation behavior of the CPU-CNTs systems. It is established, that the conducting percolation cluster for the system, formed under the action of dcEF takes place at the lower CNTs concentration, than for the system, formed without the deEF action. The percolation threshold value for the systems, formed under the dcEF action is $0.12 \%$, while for the systems, formed without the field is $0.63 \%$. This effect takes place due to the orientation of CNTs and their clusters in the dc electric field.

Proposed methods of the percolation thresholds decreasing can be used for creation of the novel polymeric nanocomposites based on polyurethanes with improved functional properties.

\section{References}

1. H.Koerner, W.Liu, M.Alexander, P.Mirau et al., Polymer, 46, 4405 (2005).

2. E.A.Lysenkov, Z.O.Gagolkina, E.V.Lobko et al., Functional Materials, 22, 342 (2015).

3. S.D.Bergin, Z.Sun, P.Streich et al., J.Phys. Chem. C, 114, 231 (2010).

4. E.A.Lysenkov, Y.V.Yakovlev, V.V.Klepko, Ukr.J.Phys., 58, 378 (2013).

5. N.I.Lebovka, E.A.Lysenkov, A.I.Goncharuk et al., J.Compos. Mater., 45, 2555 (2011).

6. E.A.Lysenkov, N.I.Lebovka, Y.V.Yakovlev et al., Compos. Sci. Technol., 72, 1191 (2012).

7. S.Pack, T.Kashiwagi, D.Stemp et al., Macromolec., 42, 6698 (2009).

8. Q.Mei, J.Wang, Z.Huang, Acta Mater.Compos.Sin., 25, 146 (2008).

9. H.Palza, B.Reznik, M.Wilhelm et al., Macromol. Mater. Eng., 297, 474 (2012).

10. M.Loginov, N.Lebovka, E.Vorobiev, J.Colloid Interface Sci., 365, 127 (2012)

11. L.Lisetski, M.Soskin, N.Lebovka, Physics of Liquid Matter: Modern Problems, Springer Proc. in Physics, ed by L.Bulavin, N.Lebovka, Springer Intern. Publishing, Switzerland (2015).

12. P.V.Kamat, K.G.Thomas, S.Barazzouk et al., J.Am.Chem. Soc., 126, 10757 (2004).

13. E.A.Lysenkov, V.V.Klepko, V.M.Golovanets et al., Ukr.J. Phys., 59, 906 (2014).

14. Y.F.Zhu, C.Ma, W.Zhang et al., J.Appl.Phys., 105, 054319 (2009).

15. Technical Condition 113-03-413-89. Isocyanates. The Method of Mass Content of Isocyanate Groups (1989).

16. A.V.Melezhyk, Yu.I.Sementsov, V.V.Yanchenko, Prikl. Khim., 78, 938 (2005).

17. E.Lysenkov, I.Melnyk, L.Bulavin et al., Physics of Liquid Matter: Modern Problems, Springer Proc. in Physics, ed. by L.Bulavin, N.Lebovka, Springer International Publishing, Switzerland (2015).

18. A.Kyritsis, P.Pissis, J.Grammatikakis, $J$. Polymer Sci.: Part B: Polymer Phys., 33, 1737 (1995). 